\title{
Lugares de devoção à santa abadia no interior de Goiás: a igreja da padroeira, a praça, os residentes e visitantes
}

\section{Places of devotion to saint abadia in the interior of Goiás: the patron church, the square, residents and visitors}

Márcia Regina Feitosa Santos* Jean Carlos Vieira Santos**

\section{Resumo:}

O objetivo deste trabalho foi analisar o lugar de fé e devoção à Nossa Senhora da Abadia e compreender se, no espaço investigado - a cidade de Quirinópolis - existe algum sentido ou elementos que possibilitem a discussão da religiosidade como uma relação de fé e devoção estabelecida. Nessa perspectiva, visa-se apresentar algumas análises sobre as particularidades, as relações estabelecidas nos espaços da igreja, praça da matriz e nos espaços públicos urbanos, além de se verificar como tal devoção é constituída histórica e culturalmente. O recorte de estudo encontra-se localizado na parte central do espaço urbano do município de Quirinópolis, na microrregião homônima no interior do estado de Goiás. Para a construção do trabalho, foram fundamentais o referencial teórico (livros, jornais, internet e revistas), os trabalhos de campo, o levantamento fotográfico e a aplicação de inquéritos com 150 sujeitos presentes nas celebrações à Nossa Senhora da Abadia, em Quirinópolis. Os principais resultados apontam para um grupo de sujeitos de base local e regional que planejam, organizam e fazem a festa.

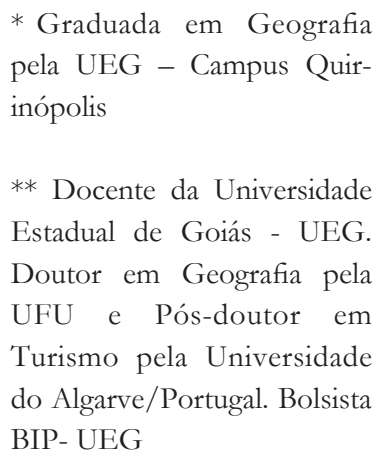
pela UEG - Campus Quirinópolis

** Docente da Universidade Estadual de Goiás - UEG. Doutor em Geografia pela UFU e Pós-doutor em Turismo pela Universidade do Algarve/Portugal. Bolsista BIP- UEG

\begin{abstract}
:
The objective of this study was to analyze the place of faith and devotion to Nossa Senhora $\mathrm{da}$ Abadia and understand if in the investigated area - the city of Quirinópolis - there is any sense or elements that allow the discussion of religion as an established relationship of faith and devotion. From this perspective, it aims to present some analysis about the particularities, the relations established in the spaces of the church, the main church square and in urban public spaces, in addition to verify how this devotion is historical and culturally constituted. The study clipping is located in the central part of the urban area of Quirinópolis, in the homonymous micro-region in the state of Goiás. To the construction of this work, the theoretical background (books, newspapers, internet and magazines), the fieldwork, the photographic survey and the application of surveys with 150 individuals present at the celebrations to Nossa Senhora da Abadia, in Quirinópolis. The main results point to a group of subjects of local and regional basis that plan, organize and make the party.
\end{abstract}

Palavras-chave:

Espaço religioso, Quirinópolis, Lugar

Key-Words:

Religious Space, Quirinópolis, Place 


\section{INTRODUÇÃO}

I nicialmente, é importante lembrar que várias cidades do mundo se destacam como lugares de devoção e fé religiosa, além de se consagrarem economicamente a partir do desenvolvimento do turismo religioso, gerando emprego e renda aos seus moradores durante o ano todo. Entre os exemplos mais conhecidos, há a peregrinação no caminho de Santiago de Compostela (Espanha), a devoção à Fátima (Portugal), a devoção à Nossa Senhora Caacupé (Paraguai), à Nossa Senhora de Lourdes (França), entre outros lugares internacionais, como Jerusalém e Vaticano.

No caso do Brasil, podemos citar a devoção a Padre Cícero em Juazeiro do Norte, no Nordeste brasileiro; Círio de Nazaré, em Belém (Pará); as peregrinações de Nossa Senhora da Abadia, em Ituiutaba e Romaria (Minas Gerais); e o santuário de Nossa Senhora da Conceição Aparecida, na cidade de Aparecida, interior de São Paulo, considerada pelos católicos a padroeira do Brasil, tendo como ponto alto dos festejos o dia 12 de outubro - é o espaço religioso mais visitado do país.

Sobretudo no estado de Goiás, pode-se destacar a cidade de Trindade e a devoção ao Divino Pai Eterno ${ }^{1}$, mas outros espaços são evidenciados: Caldas Novas, pela devoção à Nossa Senhora da Salete; Muquém, pela peregrinação de Nossa Senhora da Abadia; a festa da padroeira Nossa Senhora D'Abadia, em Abadiânia e Cachoeira Alta; as celebrações do Divino Espírito Santo, em Pirenópolis; e a procissão do fogaréu durante a Sexta-Feira da Paixão, na cidade histórica de Goiás.

Santos (2010, p. 85) lembra, em seu trabalho, que as festas e romarias de Trindade e Muquém são relevantes em Goiás; segundo esse autor, a "[...] Basílica do Divino Pai Eterno em Trindade recebe turistas de várias partes do Brasil, colocando o município como principal destino turístico religioso do estado de Goiás".

De acordo com D’Abadia (2014), as raízes da romaria de Trindade se relacionam a uma economia de base agrária, ou seja, rural. O primeiro visitante/romeiro do lugar é o criador de gado, o agricultor que, no período da entressafra, deixa a lida do campo para louvar, agradecer e pedir novas bênçãos para a próxima semeadura e o seu rebanho.

Nesse contexto, o objetivo do presente trabalho foi analisar o lugar de fé e devoção à Nossa Senhora da Abadia e compreender se, no espaço investigado - a cidade de Quirinópolis - existe algum sentido ou elementos que possibilitem a discussão da religiosidade como uma relação de fé e devoção estabelecida. Nessa perspectiva, visou-se levantar algumas análises e responder aos seguintes questionamentos: Quais são as particularidades do lugar de Nossa Senhora da Abadia em Quirinópolis? Quais são as relações estabelecidas nos espaços da igreja, da praça da matriz e nos espaços públicos urbanos? Como essa devoção é constituída histórica e culturalmente?

$O$ recorte de estudo encontra-se localizado na parte central do espaço urbano do município de Quirinópolis, na microrregião homônima no interior do estado de Goiás. D’Abadia (2014), arrazoa que, em Goiás, as origens rurais e a cultura sertaneja são determinantes para a disseminação das práticas religiosas, em virtude da popularização da prática da romaria.

Nesse viés, o presente trabalho se justifica pela não existência de literatura geográfica abordando a temática religiosa associada à devoção e fé à Nossa Senhora da Abadia. E para atingir os objetivos propostos, a pesquisa parte da discussão acerca da Geografia, dos lugares de devoção e da fé religiosa católica, chegando à organização espacial dos sujeitos envolvidos com a igreja e os espaços públicos onde são desenvolvidos os movimentos que permitem a devoção à Santa.

Para a construção do trabalho, foram fundamentais o referencial teórico (livros, jornais, internet e revistas), os trabalhos de campo e a aplicação de inquéritos com 150 sujeitos visitantes presentes nas celebrações à Nossa Senhora da Abadia em Quirinópolis.

$\mathrm{Na}$ tentativa de interpretar os diferentes olhares dos indivíduos presentes nos lugares de celebração, optou-se pelo método quantitativo, aplicando a técnica de inquérito, com vistas a:

[...] dar resposta à necessidade de conhecer a população-alvo, estabelecer eventuais relações de causalidade e determinar as principais tendências, em termos de padrões espaciais. A informação acerca do grupo social que definimos foi processada de modo a tornar quantificáveis os resultados obtidos ou, pelo menos, nos casos em que pela sua própria natureza tal seja inviável, passíveis de interpretação e sistematização (SANTOS, 2006, p. 41-42).

É importante esclarecer que a escolha da pesquisa quantitativa foi feita com base nos objetivos que se deseja alcançar nesse artigo. Outra questão que merece ser destacada é o trabalho de campo, que proporciona outras leituras na Geografia e surge como "[...] um caminho para buscar, selecionar, organizar e interpretar a informação, 
que é a expressão de um momento do lugar e da vida" (SCHAFFER, 1999, p. 88).

Nesse contexto, o trabalho de campo, como técnica de análise, pode ser realizado em qualquer "[...] lugar, seja rural ou urbano, e utilizado para obtenção de informações sobre a importância das relações espaciais. Uma das funções mais importantes das investigações empíricas [...]" (MARAFON, 2009, p. 388). Marques (2011), Rezende e Santos (2013) ressaltam que o trabalho in loco, além de enriquecer a pesquisa com material ilustrativo e fontes primárias, permite ler a paisagem, espacializar a investigação e decifrar/desvendar a problemática, desenvolvendo o trabalho e buscando respostas aos questionamentos levantados.

\section{A GEOGRAFIA, OS LUGARES DE DEVOÇÃO E A FÉ RELIGIOSA CATÓLICA: PONTO DE PARTIDA CONCEITUAL}

A Geografia é uma área do conhecimento que estuda os lugares de devoção em relação à fé religiosa católica e a outras vertentes consideradas sagradas. Nesse segmento de investigação científica, estão as crenças de diferentes sujeitos, interligando elementos sociais, econômicos e culturais; é, pois, uma discussão relevante, contextualizada mesmo em cidades que não são turísticas no tocante à religião, a exemplo de Quirinópolis, no interior do estado de Goiás. Nesse contexto, Claval (1997, p. 91):

\begin{abstract}
[...] aborda a geografia religiosa através das marcas que esta imprime nas paisagens (igrejas, mesquitas, santuários, templos, cruz, etc.) pelos obstáculos que ela impõe a certos gêneros de vida (obrigação do jejum na sexta-feira, interdição do álcool e do consumo de carne de porco, por exemplo), e pelos gêneros de vida que ela faz nascer (o dos padres ou dos monges).
\end{abstract}

Diante do pensamento supracitado, a geografia cultural, ao fazer do homem o centro de sua análise, foi obrigada a desenvolver novas abordagens. Ela se constitui em torno de eixos que são igualmente necessários e complementares, partindo "[...] das sensações e das percepções; a cultura é estudada através da ótica da comunicação, que é, pois, compreendida como uma criação coletiva; a cultura é apreendida na perspectiva da construção de identidades" (CLAVAL, 1997, p. 92). Desse modo, torna-se relevante lembrar que:

O catolicismo representa parte da herança religiosa vivenciada no Brasil. O continente latino-americano é considerado a principal área colonizada pelas culturas europeias. A crença religiosa católica exerce lugar de poderio em relação a outros credos. São evidentes os vestígios nos rituais religiosos, constituindo particularidades do processo civilizatório, A religião católica está impregnada no imaginário popular, em suas tradições e práticas reveladas nas festas de padroeiros. Países como Portugal, Espanha, França, Itália e países latino-americanos são bastante estudados nas ciências sociais nos seus aspectos religiosos, despertando interesse nesse estudo geográfico (D’ABADIA, 2014, p. 203).

O catolicismo em questão apresenta algumas características próprias, visto que é criado para suprir um espaço deixado pela igreja católica nos grupos sociais do interior brasileiro. Tem sua essência cravada numa sociedade rural que, distante do catolicismo oficial proclamado pelo "[...] clero e praticado sob o teto das casas paroquiais, criou seus próprios ritos a partir da mescla do cotidiano vivido com o sagrado, percebido nas poucas visitas dos representantes da igreja" (MARQUES, 2011, p. 50).

Nas palavras de Souza (2013, p. 255), uma das práticas que valoriza as relações aos conteúdos humanos é a religião, sobretudo "[...] as rezas e festas da religião popular, como, o terço, a novena, as folias de reis, mas também as festas populares e profanas, como os bailes e o futebol'. Para D'Abadia (2003), o debate acerca da religião, como fator preponderante nos movimentos dos grupos humanos, mostra o quanto ela implica em decisões sociais que, por sua vez, são tomadas pela influência do religioso.

Nesse entremeio, o turismo religioso e suas implicações nos lugares são uma forma de:

[...] promover uma viagem, conhecer um lugar significativo para o fiel. Por exemplo, os deslocamentos periódicos aos santuários ou por ocasião das festas religiosas no Brasil. Os romeiros nome dado aos peregrinos brasileiros, geralmente realizam essas viagens para cumprirem promessas ou mesmo conhecerem os santuários dos santos de suas devoções (D’ABADIA, 2003, p. 107).

As devoções e os movimentos de fé em lugares religiosos podem acontecer de forma individual ou coletiva. Há peregrinações que buscam cumprir promessas feitas para obter determinada graça a santos, ou ainda que busquem se redimir aos pecados, se arrependendo e demonstrando sua devoção em divindades ou espíritos que julgam milagrosos.

O avanço considerável desse aspecto faz com que se questione a necessidade, ainda existente no ser humano, de crença em algo maior do que a ciência não pode explicar, em busca de explicações, de se entender como ser 
humano e de encontrar motivações para viver. D'Abadia (2003, p. 107) discorre que a peregrinação constitui “"...] um movimento carregado de prazer, satisfação espiritual. [...] como um momento de lazer". A autora ressalta que, por ser um ato religioso, a peregrinação motiva os visitantes, ano após ano, a repeti-lo numa movimentação temporária marcada no tempo sagrado de devoção religiosa.

Com base em Santos (2013, p. 36), pode-se definir o lugar religioso a partir de "[...] situações e atividades que proporcionam prazer e diversão a quem vem de fora, algumas incluem nela uma vastidão de situações diversificadas e ligadas entre si por elementos comuns".

Para alguns visitantes religiosos, o tempo de fé é também de lazer, sendo geralmente ocupado como forma de distração, evasão, divertimento ou desenvolvimento e realização pessoal; nesse caso, é um tempo de consumo de produtos religiosos e de outras infraestruturas existentes nos lugares que recebem esse segmento de turistas.

Nas cidades turísticas religiosas, os espaços de fé são caracterizados como sagrados e profanos, trazendo uma das maiores discussões científicas em áreas como Geografia, Turismo, História e Sociologia. Envolve-se, porquanto, um conjunto de pesquisadores que definem tal abordagem da seguinte maneira:

A missa, a procissão e o sermão do padre representam a marca do sagrado oficial. A dança, as frequentes bebedeiras e as brigas testemunham o profano. $\mathrm{O}$ espaço profano diretamente vinculado ao sagrado consiste do conjunto de atividades não religiosas e apresenta uma articulação com o sagrado. Compreende a área dos comerciantes e barraqueiros (ROSENDAHL, 1997, p. 132).

O ritual da construção do espaço sagrado implica em um duplo simbolismo: primeiramente, o centro do mundo se constitui em um preferencial cujo prestígio está bem determinado; em segundo lugar, a referia construção impõe uma interpretação simbólica da materialização do centro.

Nesse sentido, é possível distinguir dois elementos fundamentais no espaço sagrado: o ponto fixo e o seu entorno. No primeiro, as formas espaciais existentes cumprem funções que estão diretamente associadas à hierofania materializada no objeto impregnado do sagrado; enquanto isso, o entorno possui os elementos necessários ao crente para a realização de suas práticas e do seu roteiro devocional (ROSENDAHL, 1997).

Sendo assim, define-se o espaço sagrado como um campo de forças e de valores que eleva o "[...] homem religioso acima de si mesmo, que o transporta para um meio distinto daquele no qual transcorre sua existência. É por meio dos símbolos, dos mitos e dos ritos que o sagrado exerce sua função de mediação entre o homem e a divindade" (ROSENDAHL, 1997, p. 122).

De acordo com Marques (2011, p. 50) e Rosendahl (2005, p. 207), “[...] a dimensão do lugar nos oferece as características do catolicismo popular tradicional. O oratório é o espaço religioso nas residências". Em alguns casos, o espaço sagrado da comunidade que abriga o santo protetor e o padroeiro é uma pequena capela, caracterização teórica muito comum na zona rural do município de Quirinópolis.

Postula-se aqui o seguinte pensamento: se a missa é realizada na praça pública, essa se torna sagrada, mas, se a festa e o consumo de alimentos e bebidas ocorrem na mesma praça, pode-se defini-la como profana. Não é tarefa simples determinar o lugar enquanto sagrado ou profano, pois ele faz parte de um conjunto de relações impregnadas no cotidiano às quais o sujeito pode se entregar de livre vontade, seja para se divertir, recrear ou, ainda, praticar sua devoção e fé. A participação social é, de fato, voluntária ou motivada por vínculos familiares.

O lazer, que para muitos pode ser entendido como profano, é uma das facetas do lugar religioso, mas é preciso lembrar que tal momento de entretenimento possui outras facetas que são exploradas pelos participantes com o significado que cada um lhe atribui. Portanto, um dos segmentos dessa celebração de fé é o turismo religioso, que movimenta um número elevado de pessoas todos anos em várias localidades no mundo, sobretudo nos exemplos já citados neste artigo.

\section{OS LUGARES E A DEVOÇÃO À NOSSA SE- NHORA DA ABADIA}

As festas de devoção à Nossa Senhora da Abadia, realizadas pelas cidades do Cerrado no interior do Brasil, são vividas a cada ano por aqueles sujeitos do lugar, e tais celebrações ocorrem durante os primeiros 15 dias do mês de agosto. Nesse contexto, Marques (2011, p. 70) cita que os referidos lugares são, antes de tudo, um espaço; mas se diferenciam dele por serem um ambiente marcado por "[...]relações de identidade e pertencimento. O lugar de um indivíduo é único, particular, subjetivo. Nessa perspectiva, a constituição do lugar leva tempo, depende da vivência". 
Existe uma realidade na paisagem religiosa que é essencialmente visível. Porém, para explicá-la, é preciso apelar para os fatores invisíveis presentes nas práticas religiosas:

Essas práticas religiosas possuem um roteiro mais ou menos preestabelecido na percepção hierárquica do peregrino de viver o sagrado no espaço e no tempo. Tentar-se-á desvendar os símbolos do imaginário popular como mais um meio de conhecimento do sagrado no espaço através dos atos comportamentais de visitar a imagem e seguir a procissão, bênção d'água e a benção da saúde, fazer promessas e assistir à missa e participar dos atos religiosos. (ROSENDAHL, 1997, p. 135).

No caso da festa, fé e devoção à Santa Abadia, os referidos espaços geram e pressupõem pertencimentos. É o que se vê nas literaturas que retratam a devoção reproduzida em lugares como Abadiânia (Goiás), Muquém (município de Niquelândia, Goiás), Romaria (Alto Paranaíba de Minas Gerais), Uberaba e Ituiutaba (Minas Gerais). Nesses locais, a festa se realiza na primeira quinzena do mês de agosto.

Muquém é um pequeno aglomerado rural situado a leste no município de Niquelândia, ao norte do estado de Goiás. A principal via de acesso ao local é a GO-237, conhecida como "Rodovia da Fé" e que possui um trecho de $46 \mathrm{~km}$ nesse município, ligando a cidade ao povoado (D’ABADIA, 2003). Esse lugar abriga, no seu espaço:

[...] por mais de 200 anos, a romaria de Nossa Senhora da Abadia, que se realiza na primeira quinzena do mês de agosto. Essa festa religiosa tem como principal atrativo a celebração de uma novena para homenagear a padroeira de Goiás, onde todos os anos em peregrinação milhares de fiéis e não fiéis para lá se dirigem em busca das práticas religiosas, oportunidades de negócios e diversão, entre outros motivos, organizando nesse período uma "cidade temporária" no interior do estado. (D'ABADIA, 2003 , p. 106).

A autora citada diz que Nossa Senhora da Abadia é a padroeira do estado de Goiás. Nesses lugares de devoção ocorrem as novenas, expressadas "[...] na religiosidade, no mítico e na ação dos homens que caminham sertão adentro em busca do sentido da vida, em busca da vivência religiosa que o local proporciona" D'Abadia, (2014, p. 176).

Fundamentado nas literaturas de Urzedo (2012), Santos (2010), Sagim e Sagim Júnior (2000), é possível afirmar que o surgimento do espaço urbano de Quirinópolis está associado à sua padroeira, pois, de acordo com esses autores, a cidade se originou por volta de 1832, tendo como vetor a imigração para Goiás de sujeitos oriundos de Ouro Preto, Minas Gerais. Em 1843, outros pioneiros que se instalaram na região doaram terras à igreja católica para a criação do povoado de Abadia do Paranaíba.

Em 1879, o povoado foi elevado à freguesia, com o nome de Nossa Senhora D’Abadia do Paranaíba. Esta, por sua vez, se tornou distrito de Rio Verde em 1894 e, em 1931, recebeu a denominação de Quirinópolis. Em 1943, foi elevado à categoria de cidade, desmembrando-se de Rio Verde. O município foi instalado em 1944 pela Lei n. 8.305, de 31 de outubro de 1943.

O nome de Igreja Nossa Senhora D’Abadia surgiu em 1962, quando foi criada a Paróquia de Quirinópolis, que passou a oficializar os serviços religiosos que até então eram celebrados em Rio Verde. Seu primeiro pároco foi o Frei Remy, sendo possível afirmar que todas as cidades da microrregião de Quirinópolis têm um santo padroeiro. Santos (2010, p. 8) faz referência em seu trabalho à mensagem da festa da padroeira de Quirinópolis: "[...] Nossa Senhora d'Abadia, mostrai-nos teu Filho Jesus!". Com isso, mostra-se a importância da devoção à Santa no lugar.

Nos anos de 2014 e 2015, quando foram desenvolvidos os trabalhos de campo, observa-se que os fluxos de pessoas na cidade são intensos, principalmente pela presença dos residentes e visitantes/devotos das cidades vizinhas. Vários serviços são disponibilizados aos visitantes, como sistema bancário, telefones públicos, supermercados, bares e comércios em geral, mas não existe nesse período uma demanda em relação aos meios de hospedagens de Quirinópolis.

Sobretudo nas proximidades da igreja, os moradores aproveitam a oportunidade favorável para melhorarem ou complementarem a renda. A festa de Quirinópolis é um acontecimento esperado pela população, mencionado nas memórias dos mais velhos e presente nos dias atuais. $\mathrm{O}$ envolvimento com a fé e a participação dos fiéis/residentes transformam o lugar, pois proporcionam rezas, procissões, bingos, leilões, barraquinhas e suas refeições, missas e outros momentos fundantes para os 15 dias de festa.

A maior transformação desse espaço é percebida nas avenidas e ruas do centro urbano, onde são realizadas as procissões, e na praça da igreja, em que ocorrem as celebrações e os momentos de fé fora do templo. O dia de Nossa Senhora da Abadia (15 de agosto) costuma ser o mais importante da festa, com a maior aglomeração de sujeitos residentes e visitantes. 
Diante disso, o que caracteriza o barracão de festejo em Quirinópolis é o espaço do Instituto São José, área vizinha à igreja. É um lugar religioso, mas também profano, bastante frequentado pelos fiéis e diferentes sujeitos que de alguma maneira, pela fé ou não, se fazem presentes no lugar. Ali estão os alimentos e outras infraestruturas de acolhimento que complementam o momento de devoção.

Sujeitos ligados ao mercado local, moradores e antigos residentes que hoje vivem em outras cidades participam dos espaços públicos e privados da festa, entrando em contato com aqueles que preparam voluntariamente o festejo. As ruas do centro da cidade, a praça da igreja matriz e a área de lazer do Lago Sol Poente, na região oeste da cidade, assumem um papel relevante para os agentes religiosos e festeiros voluntários, pois são essenciais para que esse momento aconteça, prezando pela conservação e proteção de valores religiosos antigos e modernos.

Nesses espaços públicos e privados, os sujeitos devotos estarão presentes, pois, durante os momentos de celebração, eles ocupam as vias de mobilidade que levam os fiéis ao destino principal que é a igreja matriz, onde se vive com densidade e louvor. Nesses lugares públicos as principais vias de ligação da comunidade com a igreja se festeja a alegria da visita da santa protetora e se respira um clima de reencontro.

As vias públicas do urbano de Quirinópolis se tornam um espaço de mobilidade da romaria, levando os sujeitos, durante os dias de festa, a sair de seus modos de vida e do cotidiano de trabalho, uma vez que se deslocam de suas casas por meio de diversos meios de transportes tradicionais ou modernos em direção à igreja, ao passo que outros chegam também caminhando de diferentes bairros da cidade. É comum o uso do carro de boi durante o festejo, tornando-se um atrativo para aqueles que não tiveram a oportunidade de conhecer esse meio de transporte e fazendo com que os antigos sujeitos do lugar revivam as tradições de ruralidade.

Nesse entremeio, os conteúdos de ruralidade e os modos de vida dos lugares de Goiás estão na bagagem da festa, o que podemos considerar um atrativo turístico. Não se pode negar que o momento religioso aqui pesquisado existe e faz parte dos espaços públicos e privados da cidade de Quirinópolis, em que os sujeitos se apropriam desses territórios para que o evento aconteça. É um período de devoção dos sujeitos locais, de agradecimento a um ser maior, motivado pela fé em Nossa Senhora da Abadia, sendo que há um envolvimento de grande parte da comunidade local.

A festa de Nossa Senhora da Abadia foi noticiada em diversos meios de comunicação da cidade - emissoras de rádio, jornais impressos, internet (blog e Facebook), cartazes, faixas, entre outras formas de divulgação - essas ações realizadas pelos sujeitos voluntários contribuem para que o evento aconteça. Marques (2011, p. 74) complementa dizendo que "[...] a globalização com suas redes de interação e comunicação são fatores que modificam diferentemente a cultura popular e as festas".

Apesar de não ser uma festa turística religiosa de abrangência nacional, pode-se afirmar que os meios de comunicação supramencionados têm influenciado diretamente a visibilidade da festa de Nossa Senhora da Abadia em Quirinópolis. Acredita-se que, se comparada com as festas anteriores ao ano de 2014, a cada novo ano a projeção midiática é maior.

Marques (2011, p. 75) pondera que a cobertura da mídia se configura "[...] como um fator determinante para o acréscimo de espectadores na festa”. Poderá, nesse caso, haver um aumento da demanda? Não sabemos ainda, mas a presença da mídia na festa tem o poder de promover sensibilizações e sociabilidades dos sujeitos, por meio de suas "[...] redes sociais que são componentes primordiais no ordenamento regional [...]" (SANTOS, 2010, p. 244).

De fato, na festa religiosa quirinopolina o sentido de divulgação acontece diretamente com a participação do devoto e com o apoio do poder público local. A mídia da festa se manifesta e se afirma nas procissões, no cultuar e nas ações de devoção, o que não deixa de proporcionar momentos de socialização e lazer.

Nesse sentido, a originalidade, a reinvenção das raízes e das tradições rurais na cidade e a redescoberta e incorporação do evento em algumas vias públicas e pelas ações midiáticas voluntárias da comunidade são alguns caminhos percebidos durante os trabalhos de campo. Por meio deles foi trilhada uma busca de concretizar um festejo que é do lugar, com sua espetacularização e pelo verdadeiro sentido do encontro de sujeitos que vivem sua devoção e alegria de pertencer a Quirinópolis.

\section{PARTICULARIDADES NOS DIAS DE FESTA EM QUIRINÓPOLIS}

O lugar da festa de Nossa Senhora da Abadia é marcado por uma paisagem urbana repleta de particula- 
ridades que pressupõem a identificação com o território, com sua musicalidade, as tradições rurais e sua cozinha; entre elas está a arte de cozinhar goiana. Durante o evento, é possível encontrar receitas interessantes (e até inusitadas) que fazem parte do gosto popular regional.

Tais alimentos cotidianamente estão na mesa de cozinhas rurais, podendo ser destacados: o arroz com carne de galinha, bovina e suína; o pequi, fruto nativo do Cerrado; as farinhas de mandioca e milho; as pamonhas e a chica doida; os doces; além de diversos biscoitos. Um dos principais atrativos da culinária local é o prato chica doida, que teve origem pelas mãos de:

Dona Petronilha Ferreira Cabral e o marido João Batista da Rocha foram os responsáveis pela criação do prato goiano (foi criado por volta de 1958), pois gostavam de reunir a família e os amigos para as pamonhadas. Conta a história que em uma dessas pamonhadas as palhas de milho acabaram e como ainda havia muita massa resolveram inventar um prato, e no contexto da literatura regional "[...] criaram a receita acrescentando à massa já temperada, queijo, linguiça, jiló, cebola e outros condimentos e levaram ao forno para assar (SANTOS, 2010, p. 216).

A culinária é uma atração local que seduz os visitantes, embora ainda não existam projetos da comunidade e discussões fora do seio político em Quirinópolis para valorizá-la como identidade do cerrado goiano, visando ressaltá-la como elemento importante de um futuro "destino turístico regional" da festa de Nossa Senhora da Abadia. Boa parte das particularidades desse momento religioso estão ligadas aos conteúdos de ruralidade do lugar, como os carros de boi e animais do meio rural, além da musicalidade de raízes religiosa e sertaneja do cerrado goiano.

Sendo a festa de Nossa Senhora de Abadia de Quirinópolis um acontecimento esperado por grande parte da população, nos alpendres das casas o fiel católico monta um oratório numa mesa pequena com toalha branca, imagem da Santa, castiçais e velas retratando o altar da santa igreja. Casas, portões e ruas da cidade são adornadas com laços e fitas de cores azul e branca para simbolizar a presença da Santa naquele local - é, pois, uma forma de o fiel renovar seus votos de fé, uma tradição cristã nos dias de celebração.

A fé que alimenta todas as crenças e religiões move a humanidade, mantém a igreja e ajuda nas realizações festivas que convertem as verbas em reformas de grandes estruturas. Nesse caso, a festa "[...] carrega valores culturais das sociedades e testemunha as crenças coletivas, as representações do sagrado a uma comunidade ou à maioria de seus membros" (D’ABADIA, 2014 p. 55) - são momentos de fé que impressionam visitantes, admiradores, religiosos e sacerdotes.

Pode-se afirmar que tal período de celebração é o principal atrativo religioso para a comunidade local. No primeiro dia do mês de agosto, por exemplo, numa sexta-feira, ocorreu a abertura oficial da festa, com quermesse e leilão (este teve as prendas doadas pelo comércio e por frequentadores da igreja católica), em que as rendas obtidas por meio desses acontecimentos são revertidas para a igreja.

Em todos os dias de festa há uma comemoração diferente: a igreja e a praça são ocupadas para festividade religiosa com momentos de adoração, rezas, terços e missas em louvor à Santa, além do pagamento de promessas pelos sujeitos devotos.

No tocante ao pátio do Instituto São José, este vira palco de grandes atrações religiosas onde são montadas as barracas de comidas típicas para as cinco noites de quermesse. Nos dias seguintes de festa acontecem bênçãos para os motociclistas e suas motocicletas às 18 horas no Lago do Sol Poente; na sequência, eles passeiam pelas ruas da cidade.

Rezas e entrega de terços e chaveiros benzidos para os fiéis também fazem parte do festejo. No sexto dia, os cidadãos de várias partes da cidade saem das capelas em áreas periféricas e vão em precisões pelas ruas e até a matriz, para iniciar o primeiro dia da novena.

A cada dia da novena, o padre faz bênçãos para toda a cidade - escolas, hospitais, comunidades etc. A cavalgada, que é muito esperada, acontece no quinto dia da novena e no décimo dia de festa; ela se inicia no Parque de Exposição da cidade de Quirinópolis e passa pelas ruas principais. Pelo fato de ela ocorrer em um domingo, várias pessoas vão às ruas para prestigiar o desfile de bois e receber a benção do padre que, por sua vez, lidera a cavalgada.

No desfile, há um carro de boi adornado de flores para carregar a imagem da Santa Nossa Senhora da Abadia, comovendo os fiéis com lembranças de um passado misturado à fé. Para finalizar, é realizado um almoço com as comunidades de diversas regiões rurais do município no barracão do Instituto São José. Esse momento conta também com apresentações culturais, a exemplo da companhia de Folia de Reis Magos do Oriente, que canta músicas relacionadas à história da Nossa Senhora da Abadia, emocionando a plateia.

A festa também conta com uma missa em que há canções sertanejas, uma maneira especial de realizar a novena com momentos de benção para os alimentos produzidos nas zonas rurais. Outro evento de grande participação de adultos e crianças acontece no dia 15: o passeio ciclístico, muito comentado entre os fiéis por ser um momento de descontração ao som de músicas em louvor à Santa. Na sequência serão apresentados os resultados da pesquisa com os sujeitos pre- 
sentes no lugar de fé e devoção.

4. CONHECENDO OS RESIDENTES E VISITANTES PRESENTES NOS LUGARES DE RELIGIOSIDADE À NOSSA SENHORA DA ABADIA EM QUIRINÓPOLIS

Inicialmente, é fundamental esclarecer que os sujeitos foram entrevistados durante todos os dias de festa e abordados nos espaços públicos de Quirinópolis e nos lugares da Santa Abadia. Aplicou-se um total 150 questionários com 16 perguntas, em que se constatou que $78 \%$ dos entrevistados são do sexo feminino e $22 \%$, do masculino.

Notou-se, durante os trabalhos de campo na cidade de Quirinópolis, que a figura feminina está mais presente e participante durante os dias de celebração e festa da padroeira. Existem fortes relações sociais femininas na produção do espaço religioso, com suas territorialidades e patrimônios.

Ao analisar os resultados que estão presentes na Figura 1, é possível compreender que as profissões dos fiéis ou participantes da festa da Padroeira Nossa Senhora de Abadia são diversas, destacando-se aposentados, estudantes e donas de casa (aqui denominadas como "do lar").

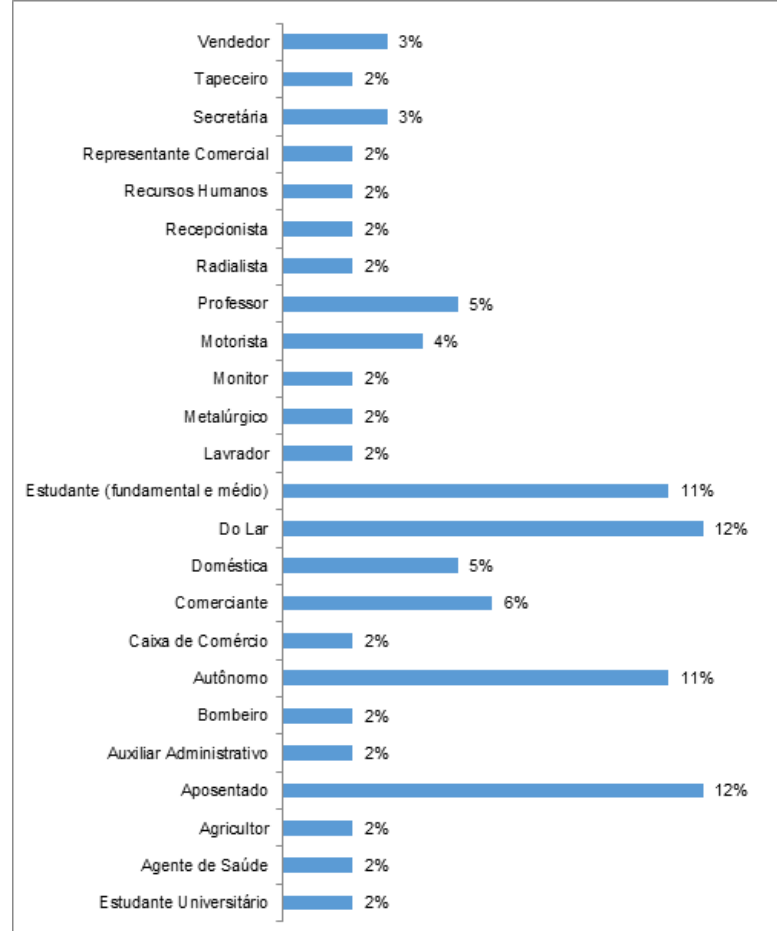

Figura 1- Profissão dos participantes da festa da Padroeira

Por meio dos resultados da Figura 2, é possível conhecer a prática religiosa dos sujeitos que se faziam presentes nos espaços públicos e na igreja durante a festa da padroeira.
A maioria (90\%) afirmou que são fiéis da igreja católica, porém uma porcentagem menor, mesmo não sendo católica, participa dos festejos, como espíritas, evangélicos, protestantes e testemunhas de Jeová.

De acordo com os depoimentos informais dos organizadores da festa, eles disseram que não conseguem distinguir quem são os sujeitos de outras religiões que se fazem presentes no lugar da Santa Abadia.

Figura 2

A religião dos participantes da festa da Padroeira

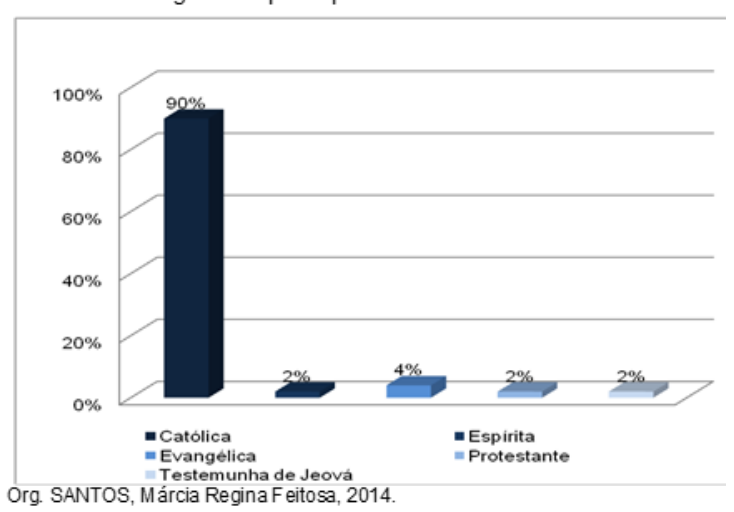

Figura 2- Distribuição dos participantes da festa segundo sua religião

Com relação aos resultados elencados na Figura 3, foi possível identificar que poucos fiéis são de cidades vizinhas. Com destaque maior para os moradores do município de Aparecida do Rio Doce. Uma questão interessante a considerar nesse resultado é que apesar de uma maior participação local, a festa atrai um número satisfatório de visitantes da região, mostrando $2 \%$ da cidade de Ipiaçu do estado vizinho de Minas Gerais.

A Figura 4 relaciona os resultados à participação dos sujeitos entrevistados nos últimos anos em que a festa da padroeira vem ocorrendo. Segundo $10 \%$ dos sujeitos inquiridos, essa é a primeira vez que participam, e a maioria (44\%) já participou da festa cinco ou mais vezes. Outros $8 \%$ não participam da festa, mas alguns lembram que ficam apenas nas vias públicas observando o momento de celebração.

Os resultados enfatizados na Figura 5, sobre a divulgação da festa de Nossa Senhora de Abadia durante o mês de agosto, mostram uma realidade em que os inquiridos responderam mais de uma questão; por isso, a soma desses dados não apontará a soma exata de 100\%. Nesse sentido, 18\% dos sujeitos entrevistados souberam da festa pelo rádio; outros $8 \%$, pela internet; $36 \%$, por amigos ou parentes; leram em cartazes, $12 \%$, em faixas, $0 \%$, pelas missas, $36 \%$ e, por passeatas de carros de som, $8 \%$ - tais veículos de informação 
procuram percorrer toda a cidade.

Figura 3.

Local de residência dos entrevistados da festa da Padroeira.

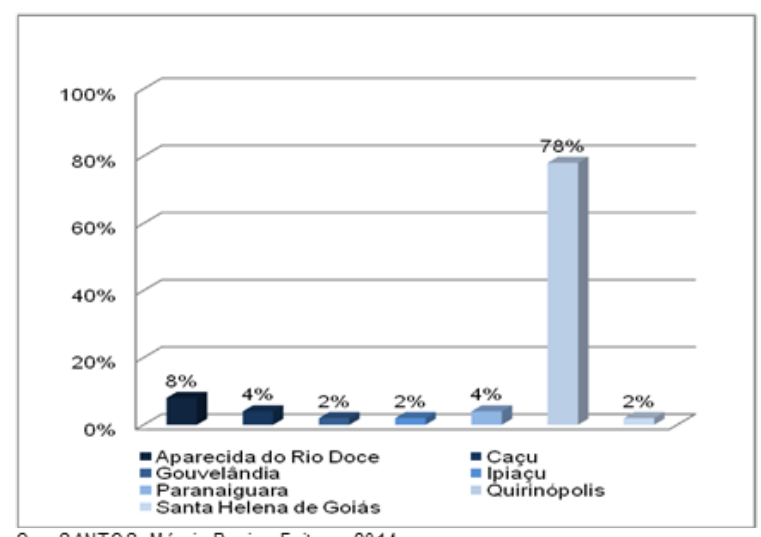

Org. SANTOS, Márcia Regina Feitosa, 2014.

Figura 3- Local de residência dos entrevistados da festa da Padroeira

Figura 4

Participações dos Sujeitos na festa da Padroeira.

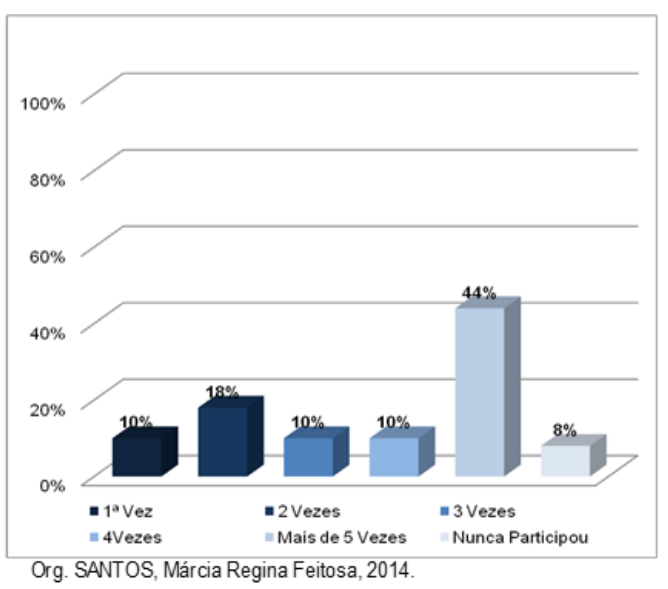

Figura 4- Frequência de participação dos entrevistados na festa da Padroeira

Ao indagar sobre a infraestrutura de acolhimento dos fiéis e visitantes na festa da padroeira, a Figura 6 mostra que grande parte dos sujeitos afirma que estão satisfeitos. Para $48 \%$ dos inquiridos, está ótima e, para 10\%, a infraestrutura precisa melhorar.

Na Figura 7, apresentam-se as opiniões dos inquiridos sobre as particularidades do lugar de celebração. Para eles, o melhor momento se refere ao sagrado, sublinhado por $42 \%$, mostrando a força da religiosidade no modo de vida local.

Com relação aos sujeitos inquiridos que já trabalharam ou são voluntários católicos nos dias de festa de Nossa Senhora da Abadia, os dados demonstram que 30\% dos entrevistados já trabalharam (ou trabalham) como voluntários nos dias de preparação, planejamento e celebração da santa padroeira, mas um grande número $(70 \%)$ prefere não ser voluntário, e sim aproveitar as festividades.

Buscamos conhecer a opinião dos inquiridos sobre a festa como potencialidade turística de Quirinópolis. De acordo com os resultados da Figura 8, é possível afirmar que para $86 \%$ a festa é um potencial turístico do município, e $14 \%$ não acreditam nesse potencial.

Figura 5

Divulgação da festa de Nossa Senhora de Abadia.

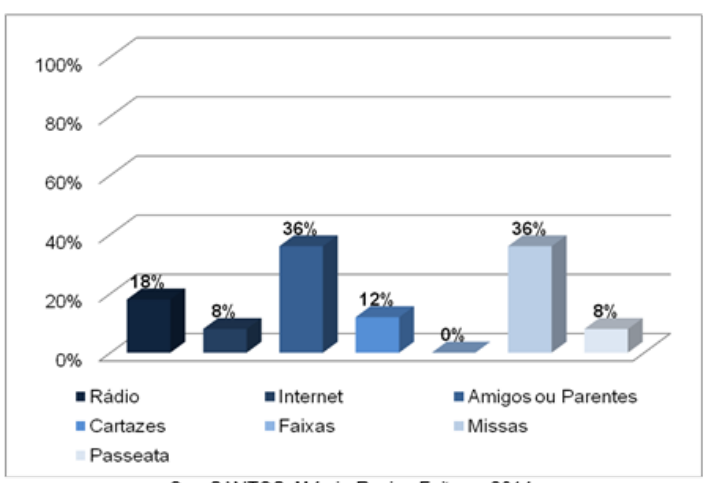

Org. SANTOS, Máráa Regina Feitosa, 2014.

Figura 5- Canais de divulgação da festa de Nossa Senhora da Abadia segundo as respostas dos entrevistados

Figura 6

Infraestrutura de acolhimento dos fiéis e visitantes na festa da Padroeira.

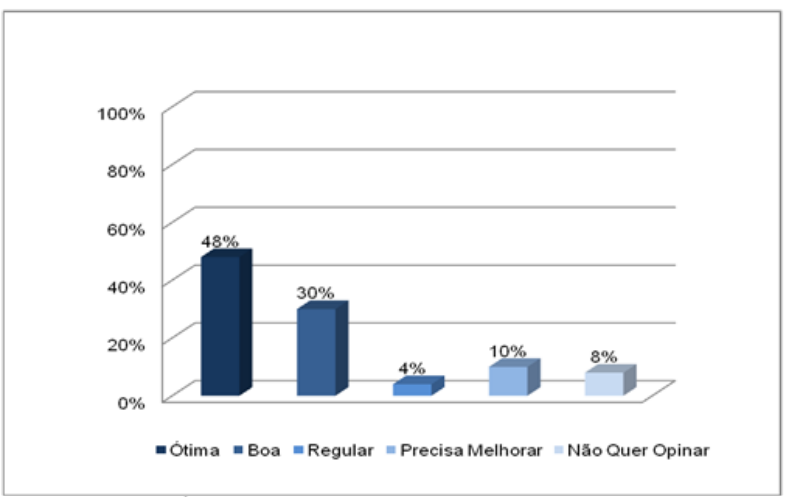

Org. SANTOS, Márcia Regina F eitosa, 2014.

Figura 6- Avaliação dos entrevistados sobre a infraestrutura de acolhida na festa da Padroeira

Dos entrevistados, $36 \%$ disseram saber da festa de Nossa Senhora da Abadia em outras cidades, enquanto $64 \%$ não sabem da existência do evento em outras localidades, apenas em Quirinópolis. Dos 36\% inquiridos que citaram ter conhecimento de outras celebrações, $6 \%$ conhecem a festa de Ituiutaba (Minas Gerais) e 16\%, a de Romaria, também em Minas Gerais. A de Muquém, no município de Niquelândia, Goiás, foi destacada por apenas $4 \%$, a mesma proporção relacionada a Cachoeira Alta, em Goiás. A festa de Uberaba, em Minas Gerais, foi apontada por $18 \%$ dos entrevistados.

Sobre a importância dos santos católicos para o estado de Goiás, especificando a devoção ao Divino 
Pai Eterno e à Nossa Senhora da Abadia, os dois com maior projeção midiática em território goiano, perguntou-se aos inquiridos sobre qual seria o santo padroeiro mais relevante do estado de Goiás. Para 10\% dos sujeitos, é a Santa Nossa Senhora da Abadia, e para 24\%, o Divino Pai Eterno. No entanto, a maioria dos entrevistados considera que os dois padroeiros são importantes, o que foi destacado por $62 \%$ dos indivíduos.

Figura 7

Particularidades da festa da Padroeira destacadas pelos Entrevistados

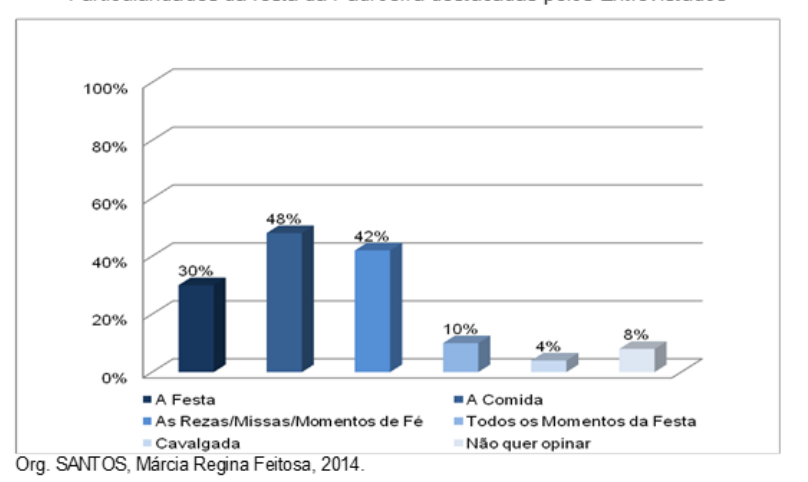

Figura 7- Particularidades da festa da Padroeira destacadas pelos entrevistados

Figura 8

O potencial turistico da festa

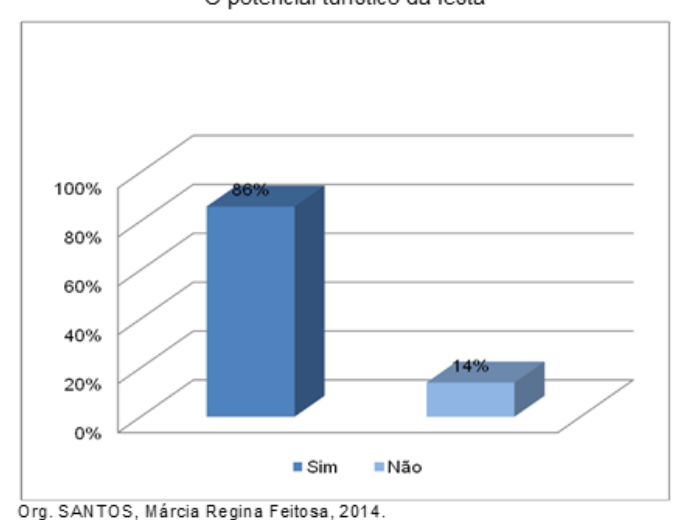

Figura 8- Opinião dos entrevistados acerca do potencial turístico da festa da Padroeira

Durante os trabalhos de campo e as aplicações dos questionários, tencionou-se conhecer a participação dos visitantes da festa da padroeira nas missas da igreja de Nossa Senhora da Abadia que são realizadas semanalmente. Nesse caso, $42 \%$ declararam não frequentar a igreja durante as missas e $58 \%$ disseram que sim. Enquanto isso, $60 \%$ afirmaram assistir missas pelo rádio e televisão, destacando informalmente as celebrações do Divino Pai Eterno na cidade de Trindade (GO) - os outros 40\% disseram não ter o mesmo hábito.

Sobre o apoio da prefeitura à festa da Padroeira em Quirinópolis, os resultados mostram que, para $62 \%$ dos su- jeitos, o evento ocorre devido ao auxilio desse órgão, $12 \%$ disseram que falta apoio, $20 \%$ dizem que tal aspecto depende do prefeito e do partido politico e $6 \%$ não têm uma opinião sobre o assunto.

\section{CONSIDERAÇÕES FINAIS}

Durante a festa de Nossa Senhora da Abadia em Quirinópolis, especificamente até o ano de 2014, não foi possível verificar romeiros que saem de outras cidades da região em direção à igreja matriz, expressando seus sentimentos místicos e sustentando sua fé e devoção. Todavia, é importante salientar que a existência de tantas religiões e os deslocamentos motivados pela fé sempre existiram, o que explica o sentido sagrado de determinados lugares que atraem diversas pessoas.

Para os fiéis presentes no lugar de forte religiosidade em Quirinópolis, há dias de veneração à Santa em que eles, com fortes conteúdos de ruralidade, aproveitam as celebrações para agradecer, fazer pedidos, renovar a fé, fortalecer a ligação com a igreja católica. Além disso, tais indivíduos querem se divertir com as quermesses, as cavalgadas e as procissões, bem como aproveitar os atrativos que compõem a celebração.

Ademais, a maioria das pequenas cidades que são destinos religiosos do Brasil não tem infraestrutura necessária para receber a demanda. Além da falta de marketing e divulgação, muitos lugares são conhecidos apenas na região, havendo a necessidade de planejamento para que o turismo no local se desenvolva de maneira adequada.

A partir das leituras realizadas e citadas neste artigo, ficou explícito que uma característica marcante dos locais onde se intensificam as celebrações religiosas é o comércio, principalmente $\mathrm{o}$ ambulante, que fica à margem ou periferia da festa. É uma atividade organizada que pretende atender todo tipo de cliente, pois se farta de produtos e serviços, algo motivado pelo fluxo de pessoas; entretanto, esse fato ainda é pouco expressivo em Quirinópolis.

Grande parte da história das cidades no Brasil mostra que povoados se iniciam no entorno de uma venda e/ou de uma capela que eram construídas pelos que possuíam bens ou terras. Isso não foi diferente em Quirinópolis, pois, mesmo com o crescimento das cidades, o indivíduo, quando necessitava de um imóvel, logo procurava comprá-lo no setor central da cidade ou próximo às áreas comerciais. Destarte, convém salientar que, quando se passa pelas ruas durante a festa de Nossa Senhora da Abadia, sobremaneira no centro de Quirinópolis, é possível perceber que as casas são adornadas. 


\section{REFERÊNCIAS BIBLIOGRÁFICAS}

CLAVAL, P. As abordagens da geografia cultural. In: CASTRO, I. E. de.; GOMES, P. C. da C.; CORRÊA, R. L. (Orgs.). Explorações geográficas. Rio de Janeiro: Bertrand Brasil, 1997.

D’ABADIA, M. I. V.. Nos caminhos do Muquém: romaria e fé X turismo e lazer. In: ALMEIDA, M. G. de. Paradigmas do turismo. Goiânia: Alternativa, 2003.

D'ABADIA, M. I. V. Diversidade e identidade religiosa: uma leitura espacial dos padroeiros e seus festejos em Muquém, Abadiânia e Trindade-GO. 1. ed. São Paulo: Paco, 2014.

MARAFON, G. J. O trabalho de campo como um instrumento de trabalho para o investigador em geografia agrária. In: RAMIRES, J. C. de L.; PESSÔA, V. L. S. Geografia e pesquisa qualitativa: nas trilhas da investigação. Uberlândia: Assis, 2009.

MARQUES, L. M. A festa em nós: fluxos, coexistências e fé em Santos Reis no Distrito de Martinésia - Uberlândia (MG). 2011. Dissertação (Mestrado em Geografia) - Instituto de Geografia da Universidade Federal de Uberlândia, Uberlândia, 2011.

REZENDE, N. A. P.; SANTOS, J. C. V. Turismo científico nas cidades do entorno do Parna Emas (GO/MT/MS). In: SIMPÓSIO DE TURISMO SERTANEJO, 7., Ituiutaba, 2013. Anais... Ituiutaba: UFU, 2013.

ROSENDAHL, Z. O sagrado e o espaço. In: CASTRO, I. E. de.; GOMES, P. C. da C.; CORRÊA, R. L. (Orgs.). Explorações geográficas. Rio de Janeiro: Bertrand Brasil, 1997.

ROSENDAHL, Z. Território e territorialidade: uma perspectiva geográfica para o estudo religioso. In: ROSENDAHL, Z.; CORRÊA, R. L. Geografia: temas sobre cultura e espaço. Rio de Janeiro: EdUERJ, 2005.

SAGIM JÚNIOR, O.; SAGIM, M. B. Quirinópolis histórico. Goiânia: O Popular, 2000.

SANTOS, J. C. V. Políticas de Regionalização e Criação de Destinos Turísticos entre o Lago de São Simão e a
Lagoa Santa no Baixo Paranaíba Goiano. 2010. 367 f. Tese (Doutorado em Geografia) - Programa de Pós-graduação em Geografia do Instituto de Geografia da Universidade Federal de Uberlândia, Uberlândia, 2010.

SANTOS, M. G. M. P. Espiritualidade, turismo e território. Estoril: Principia, 2006.

SCHAFFER, N. O. Ler a paisagem, o mapa, o livro: escrever nas linguagens da Geografia. In: NEVES, I. C. B. Ler e escrever: compromisso de todas as áreas. Porto Alegre: Editora da Universidade Federal do Rio Grande do Sul, 1999.

SOUZA, E. A. O Território e as estratégias de permanência camponesa da comunidade Pedra Lisa no processo de expansão das lavouras de cana-de-açúcar, em Quirinópolis (GO). 2013. Tese (Doutorado em Geografia) - Instituto de Geografia da Universidade Federal de Uberlândia, Uberlândia, 2013.

URZEDO, M. da F. A. Quirinópolis - mãos e olhares II: história \& imagem. Goiânia: Kelps, 2012.

Correspondência dos autores:

Jean Carlos Vieira Santos

e-mail: svcjean@yahoo.com.br

Márcia Regina Feitosa Santos

e-mail: marcia.r.feitosa@hotmail.com

Artigo recebido em: 12/10/2015

Revisado pelos autores em: 20/032016

Aceito para publicação em: 07/09/2016 